including mental health, occupational health nursing jobs are clearly defined in the law.

\section{8d THROUGH THE LOOKING GLASS: THE FUTURE ROLE OF OCCUPATIONAL HEALTH NURSING}

P Orton*. Durban University of Technology, Durban, South Africa

\subsection{6/oemed-2018-ICOHabstracts.1019}

Introduction Health care delivery is under pressure throughout the world and as such is experiencing many challenges related to demands to deliver affordable, accessible and appropriate health care to the world`s population. Occupational health nurses $(\mathrm{OHN})$ have an important role to play in the delivery of universal health coverage. It is important for OHNs to be flexible and dynamic enough to embrace the evolution of health care delivery and be part of it otherwise it runs the risk of becoming redundant.

Methods A review of the literature was conducted following a search of bibliographic databases including Cinhal Plus, Medline, Academic search complete, ERIC and MasterFILE Premier. Only English language literature published between 2007 and 2017 was searched, using search terms such as, but not limited to, future of nursing, role of occupational health nursing, future role of $\mathrm{OHN}$, global health, sustainable development goals, universal health coverage and occupational health nursing education.

Results The future of OHN is dependent on the health system of the country in which the $\mathrm{OH}$ services are being delivered but it should be embedded in a model of universal health coverage and part of the overall health delivery system. OHNs will need to ensure that it is part of the current and emerging trends in global health in order to remain relevant and effective.

Conclusion OHNs will be the interface between the health system and working populations in improving health and quality of life. OHNs are important in delivering health services to a hard to reach population of adult workers who do not have time to attend to their health needs and particularly preventative health strategies such as immunisation. OHNs will be pivotal in the early detection of emerging diseases related to globalisation and climate change, which need inter-professional collaboration and teamwork across multiple sectors for joint action.

\section{SUPPORTING PREPAREDNESS FOR WORK LIFE AMONG THE UNEMPLOYED - FOCUS ON HEALTH CARE AND NETWORK COMMUNITIES}

Lappalainen Kirsi*. PD, Senior Specialist, Finnish Institute of Occupational Health, Kuopio, Finland

10.1136/oemed-2018-ICOHabstracts. 1020

Introduction This study is part of the Occupational Health Counselling project carried out in Kuopio in 2008-2010, the participants of which were 16-24 year-old young people who were not covered by OHS, and 25-54 year-old people participating in labour force training. The aim of the study was to evaluate the implementation of the customer process in health care for the unemployed and authorities' collaboration networks.
Methods The study comprised four sub-studies. The first and second sub-study consisted of interviewing authorities' personnel in Kuopio and in the control municipalities. A network questionnaire was sent out at the same time. The third substudy examined the lifestyle and health issues of the unemployed young people according to length of unemployment. In the fourth sub-study, we interviewed the young participants of the project and performed a customer feedback survey.

Result Tensions and differing opinions exist within health care services regarding the special needs of this group. The cooperation between health services and labour administration is not sufficiently solid to support the work ability of the unemployed. The research indicated that young men were at a higher risk of prolonged unemployment than women. The study also showed possible associations between prolonged unemployment and both drug use and a low or moderate score on the Work ability index.

Discussion Co-operation within health care services needs to be improved, and roles made clearer. Some of the operating concepts of OHS offer a good model as regards the needs of this customer group. OHS resources should especially focus on unemployed people who report feeling that their health or work ability has diminished. Young people in particular feel that they benefit from health promotion and health appointments with a professional.

\section{THE FEDERATION OF OCCUPATIONAL HEALTH NURSES WITHIN THE EU (FOHNEU) CELEBRATES THE 25TH ANNIVERSARY}

HE Hirdi*. Federation of Occupational Health Nurses within the EU, EU

\subsection{6/oemed-2018-ICOHabstracts. 1021}

Introduction Professional organisations and associations of occupational nursing can play a key role in the development of the speciality. The Federation of Occupational Health Nurses within the European Union (FOHNEU) was established on March 21 st 1993 in Windsor, United Kingdom. The Federation was founded by seven countries: Belgium, Denmark, France, Germany, Greece, the Netherlands, and the United Kingdom. The aim was to represent the voice of Occupational Health Nursing within the EU in order to promote the Health, Safety and Well-Being of the European Workforce. FOHNEU is open to all $\mathrm{OH}$ nursing organisations in the EU. In 2002 the FOHNEU Executive Board decided to establish a Twinning Project. The objective was to approach fellow Occupational Health Nurses in the Accession Countries.

Methods In 2017, a cross-sectional survey was conducted asking country representatives of FOHNEU to complete a questionnaire exploring the characteristics and activities of their associations in FOHNEU. The archives and memories of the Federation were also explored.

Results The network and good collaboration with partner organisations is key to a continuous development and successful achievement of goals. It can be stated that FOHNEU has played a vital role in the development of occupational health nursing education over the past 25 years. The 1 st edition of the FOHNEU Core Curriculum was launched in 1996, followed by revised editions in 2002 and 2014. FOHNEU also contributed to the WHO document on 'The Role of the Occupational Health Nurse in Workplace Health Management' in 2001. The 1 st FOHNEU International Congress took place 
in Brussels, Belgium. The 7th Congress will be in 2019, which will provide possibility of knowledge and experience sharing among international delegates.

Conclusion FOHNEU has grown and changed over the past 25 years. This work give an overview about FOHNEU's history and development since the constitution. FOHNEU look forward to the continuing and developing collaborative projects through the strong links created with new and existing memberships.

\section{Occupational Health in the Chemical Industry}

\section{IMPLEMENTING GOOD PRACTICES FOR THE SAMPLING OF CHEMICALS: THE ALTREX SOFTWARE}

Frédéric Clerc*, Nicolas Bertrand, Gautier Mater. INRS, 65 boulevard Richard Lenoir, 75011 Paris, France

\subsection{6/oemed-2018-ICOHabstracts. 1022}

Introduction During their work shift, workers may be exposed to chemicals. In France, when a risk is identified to a workplace, atmospheric concentrations must be measured to determine worker's exposure.

Methods The regulatory authorities in France have published a list of Occupational Exposure Limits Values (OELV) concerning 143 substances and guidelines to establish the sampling strategy, including statistical methods to determine when exposure exceeds its OELV. This approach is similar to the one that will soon be published in the European standard EN689. Result The good practices for the sampling strategy promoted by INRS begin with a comprehensive chemical risk assessment. The similar exposure groups and the number of samples to be collected have to be determined, as well as the organisation of the sampling in the company: this is the sampling strategy. Afterwards, the statistical assessment can be performed if enough data is collected. In this situation, several computing methods can be applied, these are implemented in the open source Expostats library. To assist hygienists in designing strategies and assessing exposure, INRS launches a new version of Altrex, a web-based software that use Expostats.

Discussion The old version of Altrex required important update to conform to current good practices promoted by INRS. The good practices proposed and the assistance provided with Altrex can help industrial hygienists in performing a correct risk assessment and thus implementing appropriate risk management measures.

\section{OCCUPATIONAL EXPOSURE TO CARBON NANOTUBES: THE STATE OF KNOWLEDGE}

Guseva Canu Irina*. Institute for Work and Health, University of Lausanne, Lausanne, Switzerland

\subsection{6/oemed-2018-ICOHabstracts. 1023}

Introduction In an emerging field of nanotechnologies, assessment of exposure is an integral component of occupational and environmental epidemiology, risk assessment and management, as well as regulatory actions. This review focuses occupational exposure to carbon nanotubes (CNT).
Methods PubMed and Scopus databases were searched for period 2000-2017 using all keywords combinations based on the following structure: 'assessment' and 'exposure' and 'carbon nanotube'. The words 'assessment' and 'exposure' were alternatively replaced by 'measurement' and by 'human' and 'occupational', respectively. The word 'carbon nanotube' was alternatively replaced by 'single-walled carbon nanotube', 'double-walled carbon nanotube', 'multi-walled carbon nanotube', and their abbreviations. Only field-studies conducted in occupational settings were included. The quality of the exposure measurement protocol and results reporting were reviewed. The results were compared with the current NIOSH recommended exposure limit (REL) of $1 \mu \mathrm{g} / \mathrm{m}^{3}$ respirable elemental carbon (EC) mass-concentration as an 8 hour time-weighted average.

Result Twenty-five studies conducted in R and D laboratories, small-scale pilot-production facilities, and, more rarely, largescale primary or secondary manufacturer/user facilities in the USA (eleven), the Republic of Korea (four), Japan (four), Russia (one) and Europe (four) were reviewed. Open handling of CNT powder during the sieving, mechanical work-up, packaging, and clean-up work-tasks was classified at highest likelihood of exposure. Fourteen most recent studies measured EC concentration, although using different methods and aerosol fractions. All but one studies observed EC values exceeding the REL. The quantification of CNT agglomerates and/or CNT-contained particles lacks methodological standardisation and precluded any comparison of results.

Discussion Currently available occupational-exposure data are limited, because production and use of CNT are relatively recent and workforce sizes remain small. Due to high variability of methods and instruments used for exposure sampling and analysis and of criteria used for interpreting their results, results are difficult to compare. Further effort of methodological standardisation is warranted.

\section{PERFORMANCE OF MODELS TO ESTIMATE OCCUPATIONAL EXPOSURE}

${ }^{1} \mathrm{M}$ van Tongeren* ${ }^{2}{ }^{2} \mathrm{~J}$ Lamb. ${ }^{1}$ Centre for Occupational and Environmental Health, Centre for Epidemiology, School of Health Sciences, University of Manchester, UK; ${ }^{2}$ The Royal Zoological Society of Scotland RZSS Edinburgh Zoo, UK

\subsection{6/oemed-2018-ICOHabstracts. 1024}

Introduction Increasingly, models and tools are used by occupational hygienists, risk assessors and risk managers for estimating exposure to and risk from chemical agents in the workplace. These range from simple, screening tools (tier 1 tools) that provide conservative exposure estimate, to more complex higher tier exposure models. In Europe, tools such as ECETOC TRA, STOFFENMANAGER and ART have been developed and are used predominantly for risk assessment as part of the REACH regulations. Furthermore, tools for estimating exposure to nano-sized particles have been developed (e.g. NANOSAFER, Stoffenmanager-NANO). In recent years, several studies have been carried out to test the performance of these tools.

Methods Several studies were carried out to determine the performance of the exposure tools for chemical agents and nano-materials, including comparison with measurement data as well as inter-user comparisons.

Results The comparison of tool estimates with measurement data suggested that the tier 1 tools appear to be conservative, although 